\title{
The Efficacy of Food Handler Training: The Transtheoretical Model in Focus, Brazil, 2013
}

\author{
GARCIA, Paloma Popov Custódio \\ Department of Nutrition, Faculty of Health Sciences, University of Brasilia, Brazil. \\ E-mail: palomapopov@yahoo.com.br
}

AKUTSU, Rita de Cássia

Department of Nutrition, Faculty of Health Sciences, University of Brasilia, Brazil. E-mail: rita.akutsu@gmail.com

SAVIO, Karin Eleonora

Department of Nutrition, Faculty of Health Sciences, University of Brasilia, Brazil. E-mail: karinsavi@gmail.com

*CAMARGO, ERIKA BARBOSA (*corresponding Author)

Department of Nutrition, Faculty of Health Sciences, University of Brasilia, Brazil. E-mail: erika.barbosacamargo@gmail.com

SILVA, Izabel Cristina Rodrigues.

Department of Nutrition, Faculty of Health Sciences, University of Brasilia, Brazil.

E-mail: belbiomedica@gmail.com

Received: November 24, 2015 Accepted: December 14, 2015 Published: December 23, 2015 doi:10.5296/jss.v1i2.8618 URL: http://dx.doi.org/10.5296/jss.v1i2.8618 
Abstract

Objective - to analyze the educational intervention strategies based on the transtheoretical model, in restaurants employees

Methodology - This work is an intervention study, based on the Attitude Change Scale for Food Handlers (ACSFH); and the check-list based on the RDC 216/2004. Both instruments were applied before and after the educational intervention. The study was conducted with 263 food handlers, in 12 Community Restaurants (CR) of the Federal District (Brazil).

Results and Discussion - The internal consistency (Cronbach's $\alpha=0.90$ ) showed that the instruments were adequate. Of the 263 food handlers, $74.5 \%(\mathrm{n}=196)$ were female, $49.8 \%(\mathrm{n}$ $=131)$ had elementary education and $77.6 \%(n=204)$ were kitchen helpers. The attitude stage obtained from ACSFH in both moments of the instrument application were respectively 3.77 - Action stage and 4.06 - Maintenance, showing significant difference between the two time periods $(p=0.000)$. The results obtained from the check-lists before and after the intervention were rated as satisfactory according to Soto et al. (2009). Although rated as satisfactory, there was a statistic difference between them $(p=0.000)$. The results showed that after the education campaign there was a change for the best in the conception of good manufacturing practices (GMP). They also showed that the adoption of active methodologies associated with the diagnostic of propensity to change, based on the transtheoretical model, are efficient for practically all attitudes. These results can contribute to the adoption, in restaurants, of custom-made training strategies based on the results obtained from applying the transtheoretical model.

Keywords: food handler, transtheoretical model, GMPs, check-list, microbiological analysis.

\section{Introduction}

Quality is a subject of interest and concern in food access, where the innocuousness aspect deserves special focus (Sanlier \& Konaklioglu, 2012). The participation of the food handler in the epidemiological chain of food poisoning and other Foodborne Diseases (FbD), has been observed by several researchers (Control \& Prevention, 2013; Piacentini \& Silva, 2014).

Considering the need of sanitary control actions in the meal production area, the Brazilian National Health Surveillance Agency (ANVISA) has developed a Collegiate Board Resolution (RDC) 216 (Brazil, 2004) modified by RDC 52 (Brazil, 2014). This Brazilian resolution establishes technical regulations for GMP in food services, determining that all handlers should be periodically trained. In these, the term "food handler" is used to indicate any person who comes into direct or indirect contact with food. Thus, individuals involved in the food production and handling process must be aware of the hygiene rules (Brazil, 2014; Stock et al., 2015).

Nieto-Montenegro, Brown and LaBorde (S. Nieto-Montenegro, Brown, \& LaBorde, 2008) point out that the increase of theoretical knowledge about a particular subject does not lead necessarily to behavioral change, and that training programs should have theoretical and practical approaches at the same time (active methods). Namely, to facilitate the 
apprehension of skills, promote active learning, increase the perception of contamination risks, always considering the work environment. For these authors, there are few studies on the effect of training programs, since most studies describe the strategy but do not show their efficiency or efficacy evidenced in assessments.

Thus, the identification of the feeling that the individual has regarding changes, allows the adoption of educational strategies where the efficiency and efficacy of training programs can be measured. It is challenging to achieve changes in food handler atitudes among individuals in restaurant environment. The use of theoretical models, especially the Transtheoretical Model can help to understand different behaviors (Prochaska, Norcross, \& DiClemente, 2013). The Transtheoretical Model or Stages of change - is based on the basic premise that behavior change is a process where people can have different levels of motivation and or intention to change. This allows the planning of interventions that respond to the particular needs of individuals or groups (Cabrera \& Gustavo, 2000). This model has been applied successfully to a variety of health behaviors including sedentary behaviors, physical activity, anthropometric and dietetic profile, driving behavior, among others (de Menezes, Mingoti, Cardoso, de Deus Mendonça, \& Lopes, 2015; Han, Gabriel, \& Kohl, 2015; Kowalski, Jeznach, \& Tuokko, 2014; Wilson et al., 2015).

Note that behavior is just one of the components of the individual's attitude. It is noteworthy that the term attitude joins action and aptitude, i.e., for the attitude to be formed, behavior, cognition, and affection must be associated. In this sense, the cognitive category is composed of thoughts, beliefs, perceptions and concepts about the attitudinal object. The affective category, in turn, brings feelings and emotions associated with the attitudinal object. Finally, the behavior category includes actions or concrete intentions to act. In general, a positive attitude statement does not determine that the behavior will also be positive, and attitude alone is not a predictor of behavior (Neiva \& Mauro, 2011).

The objective of this study is to analyze the educational intervention strategies, based on the transtheoretical model, in restaurant workers.

\section{Materials and Method}

This is an intervention study based on the adaptation results of two instruments: a Change of Attitude Scale for Food Handlers (ACSFH) (Norcross, Krebs, \& Prochaska, 2011; Prochaska \& Norcross, 2001); and the check-list based on the RDC 216/2004 modified by RDC 52(Araújo, Botelho, Akutsu, \& Araújo, 2015; Brazil, 2004, 2014).

The study included all 12 Community Restaurants (CR) of the Federal District (Brazil). The sample of study subjects was based on a pilot project with a sampling error of $4 \%$ and a confidence level of $95 \%$. The final sample based on these statistical parameters was at least 60 subjects. The final study sample was 263 food handlers. The process of creation, validation and application of instruments was divided into three steps: 
Step 1 - Instrument Creation, Validation and Testing

For the creation of the ACSFH, routine activities of the food handlers were used, as well as procedures that are present in the Brazilian current food safety legislation, RDC 216/2004 (Brazil, 2004), and a literature survey to define the initial constructs of the attitude change stage (Cattai, Hintze, \& Junior, 2010b; Cuprasitrut, Srisorrachatr, \& Malai, 2011; Egan et al., 2007; Rahman, Arif, Bakar, \& bt Tambi, 2012; Sutton et al., 2003).

The elaborated instrument held 31 statements, and responses based on a five point Likert Scale, ranging from "I don't think about it or don't do that" (score 1) classified as Pre-contemplation; "I've been thinking this way" (score 2), classified as Contemplation; "I'm determined to do that" (score 3), classified as Decision; "I started doing it recently" (score 4), classified as Action; and "I have done this for a long time" (score 5) classified as Maintenance.

The ACSFH was validated by the judges technique (Pasquali, 2009), in which five nutritionist specialists were asked to assess comprehension, accuracy and adequacy of the instrument (with a $90 \%$ level of agreement). In addition, a semantic validation was performed with 10 individuals with an education similar to that of the food handlers, to check the understanding of the constructs.

In parallel, a checklist adapted from Araújo et al. (Araújo et al., 2015) and based on the RDC 216/2004 (Brazil, 2004) was used. Witch contained 34 items related directly to the everyday practices of the food handlers. This instrument is intended to ascertain compliance with the Brazilian legislation, classifying items into compliant and noncompliant. This instrument was administered by a nutritionist, trained and experienced in the Brazilian food safety legislation.

The Check-list was used for the judgment and comparison of the Restaurants. The \% criterion of items fulfillment was applied (Soto et al., 2009) classifying them as unsatisfactory $(<50 \%)$, satisfactory with restriction (between $50 \%$ and $69 \%$ ) and satisfactory $(>70 \%)$.

Both procedures (ACSFH and Checklist) were repeated six months after the first intervention. The procedures were named, for better understanding, ACSFH 1 and Check-list 1 (before the Educational Campaign) and ACSFH 2 and Check-list 2 (after the Educational Campaign).

\section{Step 2 - Pilot Study}

A pilot study was done in a similar Restaurant, excluded from the sample because it was established in 2012. Interviews were held with 31 food handlers, with level of education, job title and gender similar to the other research participants. This procedure aimed to show, through administration of the pilot questionnaire, that the intended requirements were met. The analysis of internal consistency (Cronbach's $\alpha=0.92$ ) showed that the constructs contained in ACSFH were within an acceptable repeatability interval. This analysis was confirmed by the intraclass correlation interval, in which the index found was $90 \%$ considered an excellent repeatability index. 
Step 3 - Training

The training of the food handlers was carried out in each unit, with all food handlers involved in the food production. It focused primarily on the findings of the ACSFH 1 and the Check-list 1.

Regarding the division of the groups to be trained, the food handler classified as Pre-contemplation presented no intention of change or no awareness of the need to change, based on the content premises about FbD and contamination. The handler in Contemplation presents some level of cognitive and affective component for change, but not yet having developed it. The handler in Decision positively perceived the change and thought about what could be changed. However, this individual was missing some degree of objective knowledge about FbD's and contamination, which could strengthen his/her beliefs and reinforce the affective category towards a concrete behavioral change. The handlers in Action and Maintenance had the three constructs of attitude, in which the thought, feeling and action / intention to change exist, and what will distinguish them is the time to perform the activity.

It should be noted that for purposes of the Educational Campaign, handlers were effectively divided into two groups: Group 1 - food handlers in Pre-contemplation, Contemplation, Decision and Action; Group 2 - food handlers in Maintenance. It is emphasized that the food handlers in Action were included in the first group, with the premise that the time in which the change was installed did not allow the judgment of its consolidation (less than six months) for the strategies to be dismissed for this category.

Instructional resources, affective and ludic / behavioral strategies were created or adapted for this study population. The stage of change of each individual was considered at the time of application. The resources were organized as follows:

a) "Educational kits" were distributed containing exercises and activities notebook, pencil and a comic book entitled "Hygiene and Food Safety (Alcântara \& Bezerra, 2015; Montadon \& Dias, 2010) b) educational banners were placed at strategic points (Bandoni, 2010) and used as tools during the three days of training; c) Declaration of Participation and Recognition Diploma.

After the creation of the Educational Campaign, the training occurred as follows:

- 1st day of training: the educational kits were delivered to each food handler. The main focus of this first training was to show the food handlers the importance and the danger of the $\underline{\text { FbD's }}$ and its proximity to everyday life. Exercises on this theme, addressed in the educational kit, were used as an evaluation strategy;

- 2nd day of training: a dynamics was performed demonstrating hand hygiene - in each restaurant, food handlers were divided into groups (red, purple, blue and green). Each group had a blindfolded food handler, who simulated the correct hand hygiene procedure, using gouache paint with their group color. Thus for the dynamics there was a winning team, but all food handlers received a gift and were encouraged to speak out about their feelings. 
- 3rd day of training: theoretical explanations were carried out about the standard operating procedure (SOP) and Hazard Analysis and Critical Control Points (HACCP), in addition to exercises with the materials that were in the educational kit. In the end, the food handlers who attended the training received a "Declaration of Participation" and those identified, upon the ACSFH and Check-list administration, as in the Changing Attitude Stage - Maintenance were given a "Recognition Diploma".

For the statistical analysis, the data was described in terms of scores and their respective frequencies (expressed in percentages). For the association analysis between the qualitative variables, the chi-square statistics was used. The correlation between the scores of ACSFH and the proportion (\%) of the 34 items of the Checklist in the CR's was performed by calculating the Spearman correlation coefficient. The significance level was 0.05 . The statistical package for data analysis used was the Statistical Package for Social Science ${ }^{\circledR}$ (SPSS), version 20.0.

This study was approved by the Research and Ethics Committee, under protocol number 174/11 (University of Brasilia, College of Health). According to the resolution ANS $466 / 2012$, each food handler received a presentation letter regarding the study and authorized their participation by signing the informed consent form.

\section{Results}

\subsection{Sociodemographic Profile of the Food Handlers in the Community Restaurants}

Of the 263 food handlers, $74.5 \%(n=196)$ were female. There was a statistical difference between the CR's ( $p=0.042 ; x^{2}=20.23$ ), i.e., the proportion between men and women varied between the Community Restaurants. Regarding Level of Education, 49.8\% ( $n=131)$ of handlers had primary education; 452\% $(n=119)$ secondary education; 3.4\% $(n=9)$ college education and $1.5 \%(n=4)$ were illiterate. There was a significant difference in the Level of Education of food handlers between the CR's $\left(\mathrm{p}=0.010 ; \mathrm{x}^{2}=54.79\right)$. Regarding job title, $77.6 \%(n=204)$ were kitchen assistants. For this variable there was no statistical difference between the CR's $\left(p=0.542 ; x^{2}=31.49\right)$.

\subsection{Evaluation of the ACSFH and the Checklist in the CR's before and after the Educational Campaign}

To check the attitude stage of the food handlers, the scores from both ACSFH instrument applications were averaged. The average obtained by handlers before the Educational Campaign was 3.77 , showing the action stage; after the campaign, the average was 4.06 , indicating maintenance. The difference between the averages was significant $(p=0.000)$.

Although rated as satisfactory on both occasions, there was statistically significant difference between them $(\mathrm{p}=0.000)$, which jumped from $88.5 \%$ to $95.6 \%$. This proportion ranged from $79.4 \%(\mathrm{n}=27)$ in the CR 2, before the Educational Campaign, to $97.1 \%(\mathrm{n}=33)$ in 8 of the 12 CR's after the Educational Campaign. 
4.3 Attitudinal Profile of Food Handlers in the CR's, before and after the Educational Campaign

Observing the data found in ACSFH 1 and 2, it is noted that there was a reduction in the number of handlers that declared to be in the following stages: Pre-contemplation, Contemplation, Decision and Action. It is highlighted that in ACSFH 1 there were $0.4 \%(\mathrm{n}=$ 1) in Pre-contemplation and $2.7 \%(n=7)$ in Contemplation. These stages were not identified in ACSFH 2 after the Educational Campaign. Fisher's exact test identified a significant difference in the Contemplation stage $(\mathrm{p}=0.015)$ between the two periods, occurring also a reduction in the number of handlers who self-declared in this stage, meaning that the handlers after the educational campaign, revealed a change for the best in the conception of GMPs.

There was no significant difference between the CR's for the Decision attitude, which went from $24.7 \%(n=65)$ to $18.2 \%(n=48)$ between ACSFH 1 and 2. Action was also not significantly different between the two periods, being reduced form $64.6 \%(n=170)$ to $58,2 \%(\mathrm{n}=153)$ between ACSFH 1 and 2. It is noteworthy that these handlers moved after the Educational Campaign to the Action and Maintenance stages.

The sociodemographic variables of Gender, Education Level and Job Title did not interfere in the attitude change stage when considering the two periods of ACSFH administration.

\subsection{Checklist of the CR's and the ACSFH Average before and after the Educational Campaign}

The relationship between the attitude declared by ACSFH 1 and 2 and the behavior assessed by the 34 items related to activities of food handlers by Checklist 1 and 2, respectively, were verified. The results revealed three items classified as unsatisfactory, before the Educational Campaign. Thus, these items were correlated with three ACSFH affirmative statements:

a) The item: "Temperature monitoring of the hot exposed products before, during and at the end of distribution," had a $41.7 \%$ conformity rate in Check-list 1 and still the food handlers self-declared as in Action, with an average of 3.83 in ACSFH1, the statement "I know I need take care to always keep the food hot on the distribution counter." This shows, in this case, an incongruity between the declaration and the behavior of the handler. After the Educational Campaign, this item had $100 \%$ of conformity in the Checklist 2, where there was a significant difference before and after the Educational Campaign $(p=0.030)$, although they remained in Action, averaging 4.0.

b) The item: "The handlers uniforms are compatible with the activity, changed daily, well maintained, clean and used only inside the internal facilities of the unit," received $16.7 \%$ conformity in Check-list 1, and even then the affirmative "I need to change my uniform every day" had an average of 3.80, where food handlers declared themselves in Action. After the Educational Campaign, this item acquired $100 \%$ of conformity, presenting a statistical difference before and after the Educational Campaign $(\mathrm{p}=0.001)$, and the handlers began to declare Maintenance, averaging 4.5. 
c) The item: "Food handlers don't: smoke, talk unnecessarily, sing, whistle, sneeze, spit, cough, eat, handle money or practice other acts that may contaminate food during the performance of activities," totaled $0 \%$ compliance in Check-list 1 , and so the handlers declared themselves in Action, averaging 3.53, in the affirmative "I don't talk to my colleagues when I'm doing my job." This item did not demonstrated change in conformity remaining $0.0 \%$ of conformity in Checklist 2 after the Educational Campaign, continuing in Action, averaging 3.7.

\section{Discussion}

The analysis of internal consistency (Cronbach's $\alpha=0.90$ ) showed that the questions from ACSFH were within an acceptable repeatability interval for the food handlers in this study. This analysis was confirmed by the intraclass correlation interval, and the index found was $90 \%$, considered a great repeatability index.

It should be noted that there are no similar instruments for this population with indicators as consistent as those obtained for this sample. Other instruments have been validated regarding GMP (Akutsu, Botelho, Camargo, Oliveira, \& Araújo, 2005; Araújo et al., 2015; Santos, Akutsu, Botelho, \& Zandonadi, 2012), instruments to determine the readiness for change stage (Cattai, Hintze, \& Junior, 2010a; Sutton et al., 2003), and to evaluate the understanding, knowledge, attitudes and practice obtaining an overall confidence interval of $95 \%$ (Cunha, Stedefeldt, \& Rosso, 2014).

Furthermore, a questionnaire for the assessment of hygienic-sanitary knowledge of the food handlers was also used as a tool by Park, Kwak and Chang (Park, Kwak, \& Chang, 2010). They analyzed the food security practice with 25 multiple-choice questions obtaining: in the personal hygiene content, a Cronbach's alpha of 0.381 ; in the food hygiene content, Cronbach's alpha of 0.803; and in the content of environmental hygiene, a Cronbach's alpha of 0.825 . However, none of these instruments have reliability indicators as good as those used in this work, and have not been used in an interdisciplinary way with food handlers.

It can be also be pointed out the importance of creating instruments to investigate the adequacy of legislation and the effectiveness of food safety in a period in which Brazil has been receiving major international events. Such events have been the focus of concern of sanitary surveillance authorities. This concern has materialized the effort to create instruments that examine in a brief way the sanitary quality of production (Brazil, 2013a, 2013b; Cunha et al., 2014). The tool developed and validated in this study comes, then, to meet these needs.

As for the sociodemographic profile of the food handlers, the result of this study is corroborated by studies of several researchers (Anding, Boleman, \& Thompson, 2007; Cuprasitrut et al., 2011; Kibret \& Abera, 2012; Park et al., 2010; Rahman et al., 2012).

The results demonstrated in this study, as well as by the other researchers previously mentioned, regarding the level of education and the majority presence of women in this field of activity, reflect the presence of women in care-giving and low payment professions. Therefore, it is not possible to identify whether the low payment is due to the low levels of 
education or if the low requirements of education are associated with a lower payment. This insertion in the labor market is marked more by continuity than by change. The less valued and traditionally female occupations continue to proliferate, determining the persistence of occupational niches, for example, the activities with characteristics of domestic work(Bruschini, 2007, 2013).

Several researchers (Andreotti, Baleroni, Paroschi, \& Panza, 2007; McIntyre, 2015; Vo, Le, Le, Minh, \& Nuorti, 2015; Zaccarelli, Coelho, \& Silva, 2000) point out the need to identify the educational levels to develop educational strategies directed to the female audience. The authors also used, as in this study, illustrative booklets, visual material, group discussion, practical demonstrations and training in the workplace as a form of mobilization and change. However, those studies did not show results obtained from the training, so it was not possible to verify the efficiency or efficacy of the adopted educational strategies.

Another study, based on the Level of Education of food handlers, was developed by Zaccarelli, Rabbit and Silva (Zaccarelli et al., 2000), in which they had as main objective to verify the relevance of using an educational game as an educational practice (intervention), adjusted to level of education, and to the acquisition of knowledge about hygienic-sanitary control, for kitchen and cook assistants. The study was conducted in 9 restaurants, and ranged from 5 to 10 handlers in each one. The game proved to be efficient in creating a relaxing environment, encouraging the participation of all. Again in this case there was no objective measure to evaluate the intervention.

For the evaluation of the ACSFH and the checklist in the CR's before and after the educational campaign the results of check-lists 1 and 2, administered to the CR's, were classified on both occasions as satisfactory, according to the classification of Soto et al. (Soto et al., 2009).

The results of this study showed that, even though classified as satisfactory in both occasions, there was a statistical difference in the application of the Checklist. In the opposite direction, Park, Kwak and Chang (Park et al., 2010) conducted an observational inspection, using a tool divided into three sections: personal hygiene, food hygiene and environmental hygiene, with 34 items, totaling 100 points. Before the training, the score was 57.2 of 100 points, considered low. After the training, there was an improvement, going to 63.7 points, but without a significant difference, thus rejecting the hypothesis of improvement after the intervention. This reinforces the need for concrete and constant training programs, without leaving aside the motivation. It is worth noting that the authors considered the score low despite obtaining above average scores. This is probably due to the need to fulfill practically $100 \%$ of the items in order to comply with the legislation.

When correlating the result of the score mean variation of ACSFH with the percentage of conformity items per Restaurant in the two time periods, it was observed that there was a moderate positive correlation $(\mathrm{r}=0.465)$, meaning that, in a way, the higher the positive variation score of ACSFH, the greater the number of conformity items. Another information that can be attributed to these results, is that high rates of the Check-list compliance items are not always seen by the food handler as a personal merit. 
The implementation of training for food handlers has been discussed by several authors, bringing the need to explore issues such as personal hygiene, environmental hygiene and food hygiene (Läikkö-Roto \& Nevas, 2014; Martins, Ferreira, Moreira, Hogg, \& Gestal, 2014; Murphi, Dipietro, Kock, \& Lee, 2011; S. Nieto-Montenegro, J. Brown, \& L. Laborde, 2008; Ovca, Jevšnik, \& Raspor, 2014). RDC 216 (Brazil, 2004), modified by RDC 52/201 (Brazil, 2014)also establishes that food handlers must attend training courses.

Studies are contradictory on the effects of training over the behavior of food handlers. Some authors state that training improves knowledge, but there is a disparity related to the knowledge-attitude-practice relation, .i.e., showing that knowledge alone is not enough to change practices (Park et al., 2010)

On the other hand, other authors have reported that training, using different strategies, can be transforming, changing handler practices, elucidating the relationship between training and practice of proper food handling, identifying factors that positively influence the triad knowledge, attitude and practice (Anding et al., 2007; Cunha et al., 2014; Egan et al., 2007).

What is not explained in all cited studies is the system of evaluation that should be adopted for these trainings, or whether there should be some goal to be achieved. In practice, studies show training execution without a solid theoretical framework that would anchor performance. For the present study, upon the execution of the Educational Campaign, several procedures were considered for the adequacy of this campaign. The diagnosis obtained from the Checklist and the ACSFH played a key role in improving the attitudinal profile of the food handler, and consequently the higienic-sanitary conditions of the Community Restaurants. The same was observed by Anding, Boleman and Thompson (Anding et al., 2007).

Da Cunha, Stedefeldt and Rosso (Cunha et al., 2014) conducted their training program with a workload of 10 hours, carried out in two days, with 183 food handlers. These authors also recommend that this training should take place every six months, not exceeding one year, being fundamental for appropriate practices, and in this way should not be ceased.

In synchrony with the present study, Nieto-Montenegro, Brown and LaBorde (Sergio Nieto-Montenegro et al., 2008) conducted their training program with four classes, including foodborne outbreaks, cross contamination, personal hygiene (including hand washing) and environmental hygiene. They used theoretical resources, as well as practical activities and skills sessions applied at the time of training. The classes were needed to provide theoretical content, showing the improvement of behavior change in practice.

Da Cunha, Stedefeldt and Rosso (Cunha et al., 2014) and Nieto-Montenegro, Brown and LaBorde (Sergio Nieto-Montenegro et al., 2008) adopted educational strategies similar to the present study. However, for the researchers, there was no understanding that the workers were in different stages of change and thus they needed different educational approaches, or that the assessment is a key component of the educational process.

The Fisher exact test also showed that the Maintenance stage was significantly different between the two time frames $(\mathrm{p}=0.001)$. It went from $7.6 \%(\mathrm{n}=20)$ to $23.6 \%(\mathrm{n}=62)$, as a 
result of the Educational Campaign. This dislocation of the handlers showed that the strategy of allocating workers in Action in Group 1, which by definition have the three constructs of attitude interconnected (cognitive, affective and behavioral), was fortunate because six months after the intervention the referred dislocation was identified. That's why the intervention should always consider the time that within the attitude has been modified, so that there was no regression of attitude change stage.

In another direction, Park, Kwak and Chang (Park et al., 2010) observed that after the training, there was no significant improvement in practices and behaviors analyzed by the authors, reinforcing the need for concrete and constant training programs, without leaving aside motivation. Seaman (Seaman, 2010), in a study with food handlers, found that motivation is a variable that is directly associated with positive attitudes of food safety and proper food handling practices.

Menezes (Menezes, Mingoti, Cardoso, de Deus Mendonça, \& Lopes, 2015) developed workshops in his interventions, allocating the individuals of his research according to the stage of change. According to Linden (Linden, 2011), motivating (food handlers) is an important activity and should be used in the beginning to relax them. She also reported that showing the positive aspects of the work can be used as another form of motivation.

Still regarding the attitudinal profile, there was an improvement in that category. In a study, in which handlers completed a questionnaire about the attitude before training, less than $40 \%$ declared executing 4 of the 12 activities, which included measurement of hot and cold food, thermometer use to measure cooking temperature, food cooling, and proper hand hygiene. After training, it was observed that $80 \%$ declared the execution of 8 of the 12 activities including, in general, temperature control, hand, furniture and utensils hygiene and pest control (Anding et al., 2007).

Similarly to Da Cunha, Stedefeldt and Rosso (Cunha et al., 2014), this study points out that a positive attitude may not be enough to trigger the adoption of appropriate practices in food handling. For some attitudes, it seems that the educational process based on knowledge is not sufficient and, perhaps, coercive measures should be taken to ensure food safety.

The Check-list data's item "The handlers uniforms are compatible with the activity, changed daily, well maintained, clean and used only inside the internal facilities of the unit " of this study are consistent with those obtained by Costa (Costa, 2015) in study carried out at the Federal Institute of Pernambuco.

As discussed earlier and going toward the same direction as Oliveira, Brazil and Taddei (Oliveira, Brasil, \& Taddei, 2008), this study showed inadequate sanitary practices - the handler spoke, sang, coughed, sneezed while handling food and especially did not properly perform the hand washing technique, with $100 \%$ of inadequacies.

The aforementioned authors address the need of correct food handling techniques and especially the awareness of the professionals involved, showing that training would be essential to improve sanitary hygienic conditions, consequently lower costs for the company (Oliveira et al., 2008). 
It is noteworthy that the correct technique for hand hygiene is the most important way to prevent $\mathrm{FbD}$, but the use of adornment, besides being inappropriate, from a microbiological point of view constitutes a physical risk, which can also bring harm to handlers and consumers (Sergio Nieto-Montenegro et al., 2008).

Given the matters addressed, more studies reporting methodological strategies for better understanding of food handlers must be performed, in order to resolve such risks that affect human health.

In addition, the rules on food safety and its control must be precise and rigorous. The selection of food handlers, therefore, must obey criteria that include motivation to work and to change.

\section{Conclusion}

Based on the analysis of the tests regarding the reliability of ACSFH, it was possible to observe the adequacy of the instrument to check the attitudinal profile of food handlers. Thus, the instrument can be used as a tool, associated with the Check-list, to direct educational interventions.

Regarding the efficacy of educational strategies for food handlers, the present study demonstrated that the adoption of active methodologies associated with a diagnosis of propensity to change, based on the transtheoretical model, are efficient for practically all attitudes. The exception is due to the persistence of attitudes ingrained in the Brazilian profile, shown by Da Matta (Da Mata, 2001), and that require, from the part of those responsible for training, greater effort to change.

The adoption of a research protocol that aggregates new variables is also desirable, inasmuch that is necessary to identify inconsistencies between the perception about attitudes and the daily life of the food handlers.

The study had some limitations such as the cross-sectional design, which does not establish causal relationships. In addition, there are few scientific studies that point to factors associated with assessment strategies used in continuing education.

Finally it is worth stressing the need that the trainings always be based on diagnoses made with reliable instruments and, in fact, continue aggregating new content and strategies.

\section{Acknowledgements}

We thank the Community Restaurants (CR) of the Federal District (Brazil) for receiving our research team and the food handlers for participating with commitment.

\section{References}

Akutsu, Rita de Cássia, Botelho, Raquel Braz Assunção, Camargo, Erika Barbosa, Oliveira, Karin Eleonora Savio de, \& Araújo, Wilma Maria Coelho. (2005). Adequacy of good manufacturing practices in food services. Braszilian Journal of Nutrition, 18 no.3 Campinas May/June 2005, 419-427. 
Alcântara, Cláudia Sales, \& Bezerra, José Arimatea Barros. (2015). Histórias em Quadrinhos e Educação Alimentar: limites e possibilidades. Nona Arte: Revista Brasileira de Pesquisas em Histórias em Quadrinhos, 4(1), 71-87.

Anding, J. D., Boleman, C., \& Thompson, B. (2007). Self-Reported Changes in Food Safety Behaviors among Foodservice Employees: Impact of a Retail Food Safety Education Program. Journal of Food Science Education, 6(4), 72-76.

Andreotti, A., Baleroni, F. H., Paroschi, Vanessa H. B., \& Panza, S. G. A. (2007). Importância do treinamento para manipuladores de alimentos em relação à higiene pessoal. Iniciação Científica Cesumar, 5(1), 29-33.

Araújo, Társia Gomes de, Botelho, Raquel B. A., Akutsu, Rita de Cássia C. A., \& Araújo, Wilma M. C. (2015). Conformity of food service units with legislation. Journal of Culinary Science \& Technology, 14(1), 75-89.

Bandoni, D. H. (2010). Worker Food Program. Universidade de São Paulo, São Paulo.

Brazil. (2004). Collegiate Board Resolution No. 216 of September 15, 2004. Provides for Good Practices in Technical Regulations for Food Services. Official Diary of the Union.

Brazil. (2013a). Criteria and Methodology of Classification Food Services For The FIFA WORLD CUP 2014 (Ordinance 817/2013). Brasília: Official Diary of the Union.

Brazil. (2013b). Ordinance 1139, to June 10, 2013. Sets under the Unified Health System (SUS), the responsibilities of management levels and establishes the National Guidelines for Planning, Implementation and Monitoring and Assistance Actions Assessment in Health Events Mass. (2358-1824). Brasília: Official Diary of the Union.

Brazil. (2014). Resolution collegiate no. 52 of 29 September 2014. Changes Resolution RDC No. 216 of 15 September 2004, which establishes the Technical Regulation of Good Practices for the Food Services. Official Diary of the Union.

Bruschini, M. C. A. (2007). Work and gender in Brazil in the past decade. Cadernos de Pesquisa, 37(132), 537-572.

Bruschini, M. C. A. (2013). Work of women in Brazil: continuities and changes in the period 1986-1995. Textos FCC, 17, 85.

Cabrera, A., \& Gustavo, A. (2000). El modelo transteórico del comportamiento en salud. Rev. Fac. Nac. Salud Pública, 18(2), 129-138.

Cattai, G. B. P., Hintze, L. J., \& Junior, N. N. (2010a). Internal validation stage of readiness questionnaire to change eating behavior and physical activity. Revista Paulista de Pediatria, 28(2), 194-199.

Cattai, G. B. P., Hintze, L. J., \& Junior, N. N. (2010b). Validação interna do questionário de estágio de prontidão para mudança do comportamento alimentar e de atividade física. Rev Paul Pediatr, 28(2), 194-199. 
Control, Centers for Disease, \& Prevention. (2013). Surveillance for foodborne disease outbreaks--United States, 2009-2010. MMWR. Morbidity and mortality weekly report, 62(3), 41.

Costa, P. M. (2015). Gestão e execução do Programa Nacional de Alimentação Escolar nos Institutos Federais de Educação, Ciência e Tecnologia.

Cunha, D. T., Stedefeldt, E., \& Rosso, V. V. (2014). The role of theoretical food safety training on Brazilian food handlers' knowledge, attitude and practice. Food Control, 43, 167-174.

Cuprasitrut, Thidarat, Srisorrachatr, Suwat, \& Malai, Duangjai. (2011). Food safety knowledge, attitude and practice of food handlers and microbiological and chemical food quality assessment of food for making merit for monks in Ratchathewi district, Bangkok. Asia Journal of Public Health, 2(1), 27-34.

Da Mata, R. (2001). O que faz o brasil, Brasil? : Editora Rocco.

de Menezes, Mariana Carvalho, Mingoti, Sueli Aparecida, Cardoso, Clareci Silva, de Deus Mendonça, Raquel, \& Lopes, Aline Cristine Souza. (2015). Intervention based on Transtheoretical Model promotes anthropometric and nutritional improvements-A randomized controlled trial. Eating behaviors, 17, 37-44.

Egan, M. B., Raats, M. M., Grubb, S. M., Eves, A., Lumbers, M. L., Dean, M. S., \& Adams, M. R. (2007). A review of food safety and food hygiene training studies in the commercial sector. Food Control, 18(10), 1180-1190.

Han, H., Gabriel, K. P. \& Kohl, H. W. (2015). Evaluations of Validity and Reliability of a Transtheoretical Model for Sedentary Behavior among College Students. American journal of health behavior, 39(5), 601-609.

Kibret, M., \& Abera, B. (2012). The sanitary conditions of food service establishments and food safety knowledge and practices of food handlers in Bahir Dar town. Ethiopian journal of health sciences, 22(1), 27-35.

Kowalski, K., Jeznach, A., \& Tuokko, H. A. (2014). Stages of driving behavior change within the Transtheoretical Model (TM). Journal of safety research, 50, 17-25.

Läikkö-Roto, T., \& Nevas, M. (2014). Restaurant business operators' knowledge of food hygiene and their attitudes toward official food control affect the hygiene in their restaurants. Food Control, 43, 65-73.

Linden, S. (2011). Educação Alimentar e Nutricional: algumas ferramentas de ensino. São Paulo: Varela.

Martins, R. B., Ferreira, D., Moreira, L. M., Hogg, T., \& Gestal, J. (2014). Knowledge on food hygiene of food service staff working in nursing homes and kindergartens in Porto region-Portugal. Food Control, 42, 54-62. 
McIntyre, L. (2015). The Positive Impact of Research on Policy in the FOODSAFE Food Handler Training Program in British Columbia, Canada. Paper presented at the 2015 Annual Meeting (July 25-28, 2015).

Menezes, M. C., Mingoti, S. A., Cardoso, C. S., de Deus Mendonça, R., \& Lopes, A. C. S. (2015). Intervention based on Transtheoretical Model promotes anthropometric and nutritional improvements-A randomized controlled trial. Eating behaviors, 17, 37-44.

Montadon, A., \& Dias, M. (2010). Higiene e Segurança de Alimentos: Qualidade em Quadrinhos.

Murphi, K. S., Dipietro, R. B., Kock, G., \& Lee, J. S. (2011). Does mandatory food safety training and certification for restaurant employees improve inspection outcomes?. International Journal of Hospitality Management, 30, 150-156.

Neiva, E. R., \& Mauro, T. G. (2011). Atitudes e mudança de atitudes. Psicologia social: Principais temas e vertentes, 171-203.

Nieto-Montenegro, S., Brown, J. L., \& Laborde, L. F. (2008). Development and assessment of pilot food safety education materials and training strategies of Hispanic workers in the mushroom industry using the Health Action Model. Food Control, 19, 616-633.

Nieto-Montenegro, S., Brown, J. L., \& LaBorde, L. F. (2008). Development and assessment of pilot food safety educational materials and training strategies for Hispanic workers in the mushroom industry using the Health Action Model. Food Control, 19(6), 616-633.

Norcross, J. C., Krebs, P. M., \& Prochaska, J. O. (2011). Stages of change. Journal of clinical psychology, 67(2), 143-154.

Oliveira, M. N., Brasil, A. L. D., \& Taddei, J. A. A. C. (2008). Evaluation of sanitary conditions of public and philanthropic daycare kitchens. Ciência \& Saúde Coletiva, 13(3), 1051-1060.

Ovca, A., Jevšnik, M., \& Raspor, P. (2014). Food safety awareness, knowledge and practices among students in Slovenia. Food Control, 42, 144-151.

Park, S.-H., Kwak, T.-K., \& Chang, H.-J. (2010). Evaluation of the food safety training for food handlers in restaurant operations. Nutrition research and practice, 4(1), 58-68.

Pasquali, L. (2009). Rev Esc Enferm USP, v. 43, n.

Piacentini, K. C., \& Silva, A. P. F. da. (2014). Ocorrência de Staphylococcus aureus coagulase positivo em mãos de manipuladores de alimentos de uma unidade de alimentação e nutrição. Hig. aliment, 28(230/231), 52-55.

Prochaska, J. O, \& Norcross, J. C. (2001). Stages of change. Psychotherapy: Theory, Research, Practice, Training, 38(4), 443.

Prochaska, J. O, Norcross, J. C., \& DiClemente, C. C. (2013). Applying the stages of change. Psychotherapy in Australia, 19(2), 10. 
Rahman, Md M., Arif, M. T., Bakar, K., \& bt Tambi, Z. (2012). Food Safety Knowledge, Attitude and Hygiene Practices Among The Street Food Vendors In Nothern Kuching City Sarawak.

Sanlier, N., \& Konaklioglu, E. (2012). Food safety knowledge, attitude and food handling practices of students. British Food Journal, 114(4), 469-480.

Santos, L. L., Akutsu, R. de C. C. de, Botelho, R. B. A., \& Zandonadi, R. P. (2012). Food service compliance with ISO 14001 and ISO 22000. Revista de Nutrição, 25(3), 373-380.

Seaman, P. (2010). Food hygiene training: Introducing the food hygiene training model. Food Control, 21, 381-387.

Soto, F. R. M., Cazzola, C. P. de B., Oliveira, E. de, Sakaguti, E. H., Bernardi, F., L., Dirceu, . . . Balian, S. de C. (2009). Aplicação experimental de um modelo de conduta de inspeção sanitária no comércio varejista de alimentos. Ciênc Tecnol Aliment, 29(2), 371-374.

Stock, S., Tebest, R., Westermann, K., Samel, C., Strohbücker, B., Stosch, C., . . Redaèlli, M. (2015). Implementation of an innovative hands-on training to improve adherence to hygiene rules: A feasibility Study. Nurse education today.

Sutton, K., Logue, E., Jarjoura, D., Baughman, K., Smucker, W., \& Capers, C. (2003). Assessing dietary and exercise stage of change to optimize weight loss interventions. Obesity Research, 11(5), 641-652.

Vo, T. H., Le, N. H., Le, A. T. N., Minh, N. N. T., \& Nuorti, J. P.. (2015). Knowledge, attitudes, practices and training needs of food-handlers in large canteens in Southern Vietnam. Food Control, 57, 190-194.

Wilson, J. J., Kirk, A., Hayes, K., Bradbury, I., McDonough, S., Tully, M. A, . . Bradley, J. M. (2015). Applying the Transtheoretical Model to Physical Activity Behavior in Individuals With Non-Cystic Fibrosis Bronchiectasis. Respiratory care, respcare. 04154.

Zaccarelli, E. M., Coelho, H. D. de S., \& Silva, M. E. P. (2000). The game as an educational practice in training for hygiene and sanitary control, mains and nutrition. Higiene alimentar, 14(70), 23-26.

\section{Copyright Disclaimer}

Copyright for this article is retained by the author(s), with first publication rights granted to the journal.

This is an open-access article distributed under the terms and conditions of the Creative Commons Attribution license (http://creativecommons.org/licenses/by/3.0/). 